作 (n)

$=$

$=1$

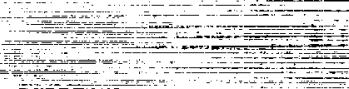

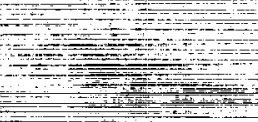

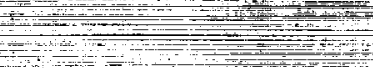

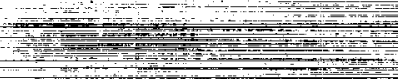

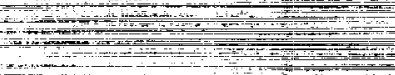

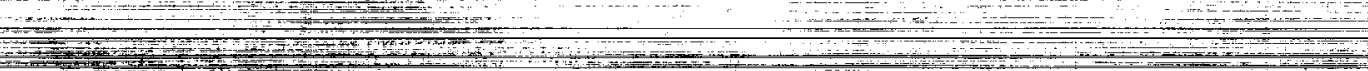

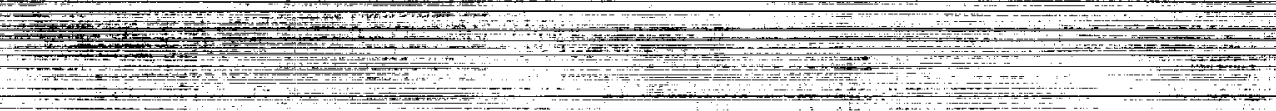

$=$

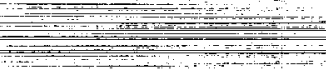

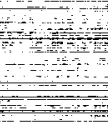

$\frac{1}{2+3}$

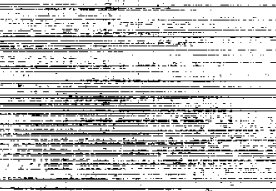

and

$=12=$

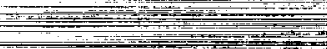

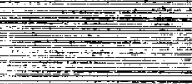

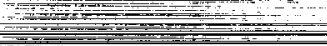

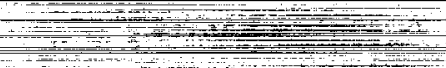

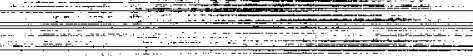

$$
=
$$

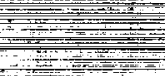

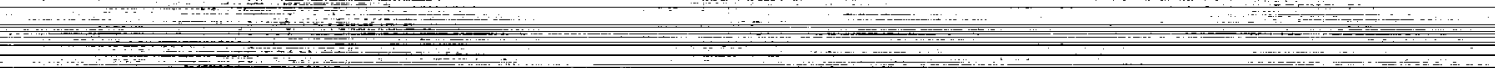$$
\text { and }
$$

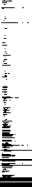

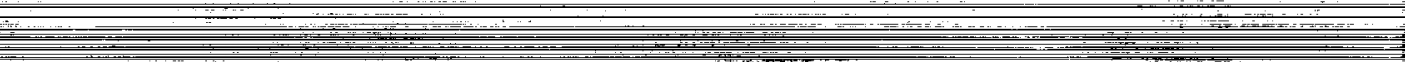

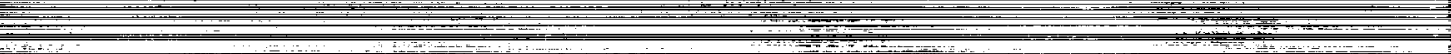
. 等
and

lon

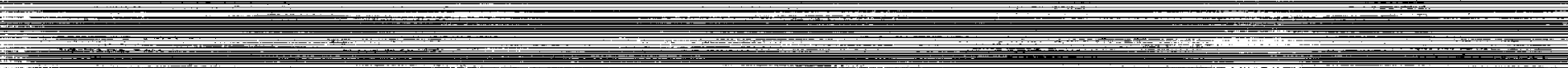

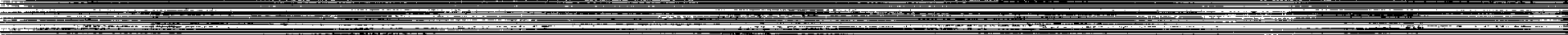

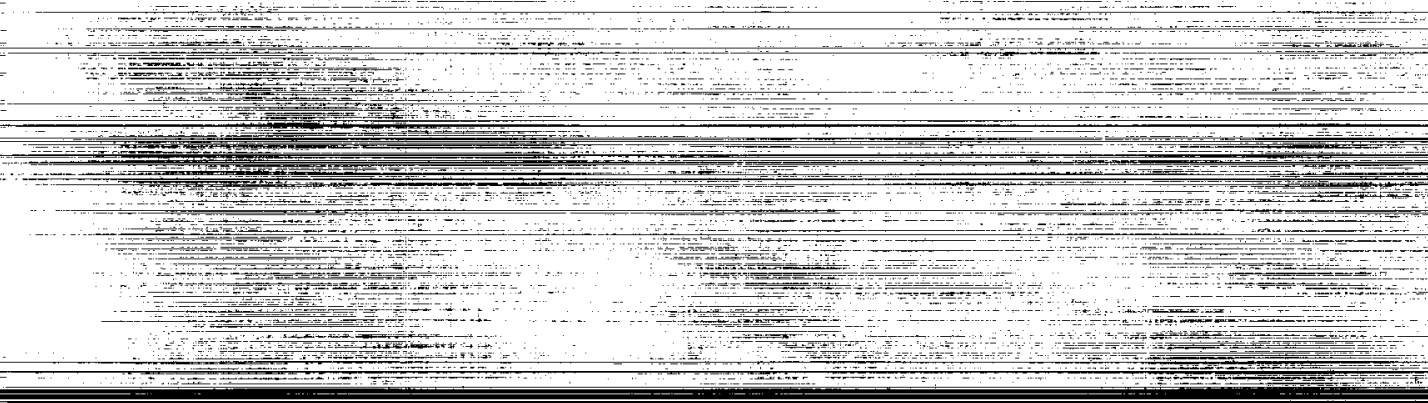


NASA Contractor Report 4395

\section{Predicted Thermal Response of a Cryogenic Fuel Tank Exposed to Simulated Aerodynamic Heating Profiles With Different Cryogens and Fill Levels}

Gregory J. Hanna

Hanna Technology Resources

Boulder, Colorado

Craig A. Stephens

PRC Inc.

Edwards, California

Prepared for

Dryden Flight Research Facility

under Contract NAS2-12722

\section{N/SA}

National Aeronautics and

Space Administration

Office of Management

Scientific and Technical

Information Program

1991 
Use of trade names or names of manufacturers in this report does not constitute an official endorsement of such products or manufacturers, either expressed or implied, by the National Aeronautics and Space Administration. 


\title{
PREDICTED THERMAL RESPONSE OF A CRYOGENIC FUEL TANK EXPOSED TO SIMULATED AERODYNAMIC HEATING PROFILES WITH DIFFERENT CRYOGENS AND FILL LEVELS
}

\author{
Gregory J. Hanna* \\ Hanna Technology Resources \\ Boulder, Colorado \\ Craig A. Stephens ** \\ PRC Inc. \\ Edwards, California
}

\begin{abstract}
A two-dimensional finite-difference thermal model was developed for the Generic Research Cryogenic Tank (GRCT). The model was used to predict the effects of heating profile, fill level, and cryogen type prior to experimental testing. These numerical predictions will assist in defining test scenarios, sensor locations, and venting requirements for the GRCT experimental tests. Boiloff rates, tank-wall and fluid temperatures, and wall heat fluxes were determined for 20 computational test cases. The test cases spanned three discrete fill levels and three heating profiles for hydrogen and nitrogen. Large temperature gradients developed in the vapor region of the tank when the vapor was allowed to stratify, but vapor mixing greatly reduced the topto-bottom temperature gradient. The thermal response of the GRCT was qualitatively similar to anticipated transatmospheric vehicle (TAV) behavior. Nitrogen simulations deviated from hydrogen simulations in several key areas, particularly where the vapor heat capacity contributed to the system thermal response. The internal radiation and wallto-vapor heat transfer effects were small compared with the effect of vapor mixing.
\end{abstract}

\section{Nomenclature}

$\begin{array}{ll}\text { A } & \text { area, } \mathrm{ft}^{2} \\ \mathrm{GN}_{2} & \text { gaseous nitrogen } \\ \mathrm{GRCT} & \text { Generic Research Cryogenic Tank } \\ h & \text { heat transfer coefficient, Btu } / \mathrm{ft}^{2} \mathrm{hr}{ }^{\circ} \mathrm{R} \\ k & \text { thermal conductivity, Btu } / \mathrm{hr} \mathrm{ft}^{\circ} \mathrm{R} \\ \mathrm{L} & \begin{array}{l}\text { distance between finite-difference } \\ \text { nodes, } \mathrm{ft}\end{array} \\ \mathrm{LH}_{2} & \text { liquid hydrogen }\end{array}$

\footnotetext{
* Consulting engineer, member AIAA.

**Mechanical engineer, member AIAA.

This paper is declared a work of the U.S. Government and is not subject to copyright protection in the United States.
}

$\begin{array}{ll}\text { LHSTF } & \text { Liquid Hydrogen Structural Test Facility } \\ \mathrm{LN}_{2} & \text { liquid nitrogen } \\ \text { NASP } & \text { National Aero-Space Plane } \\ q^{\prime \prime} & \text { heat flux, Btu/ } \mathrm{f}^{2} \mathrm{hr} \\ \mathrm{S} & \text { circumferential surface distance, } \mathrm{ft}^{\prime} \\ \text { SINDA'85 } & \begin{array}{l}\text { systems improved numerical } \\ \text { differencing analyzer }\end{array} \\ \mathrm{T} & \text { temperature, }^{\circ} \mathrm{R} \\ \text { TAV } & \text { transatmospheric vehicle } \\ \text { TRF } & \text { Thermostructures Research Facility } \\ \text { 1-D } & \text { one-dimensional } \\ \text { 2-D } & \text { two-dimensional }\end{array}$

$\begin{array}{ll}\text { Subscripts } & \\ c & \text { convection } \\ f & \text { fluid } \\ w & \text { wall }\end{array}$

\section{Introduction}

Transatmospheric vehicles (TAVs), such as the National Aero-Space Plane (NASP) will require fuselage concepts that can withstand high aerodynamic heating and an insulation system capable of reducing the heat load imposed on cryogenic hydrogen fuel. The surface temperatures associated with aerodynamic heating disqualify many standard cryogenic insulation systems. Materials such as closed-cell foams or vacuum-jacketed multilayer insulations are disqualified because of material degeneration at elevated temperatures. Thermal gradients that develop within the walls of the fuel tank could lead to high thermal stresses, which affect tank integrity. The unique combination of high thermal and mechanical loads over the vehicle surface (in close contact with the fuel tank) will require design concepts beyond the existing capability of launch vehicle and rocket 
technology. Therefore, developing new insulating systems for cryogenic hydrogen and validating fuel-tank integrity over a wide range of flight conditions will require extensive testing.

The TAV tankage systems were the subject of several experimental programs. ${ }^{(1-3)}$ These tests were an attempt to design, fabricate, and obtain experimental validation of liquid hydrogen tankage applicable to vehicles in hypersonic environments. Numerical simulation and optimization analysis of tank designs also were an integral part of experimental programs. ${ }^{(4,5)}$

In anticipation of future test requirements for TAV hydrogen systems, personnel at the NASA Dryden Flight Research Facility, Edwards, California are developing the Liquid Hydrogen Structural Test Facility (LHSTF) scheduled for completion in late 1993. The LHSTF will provide the capability of testing various full-scale and subscale flight vehicle components in simultaneous cryogenic and hightemperature environments combined with mechanical loads.

The Generic Research Cryogenic Tank (GRCT) is scheduled as the first test article for the LHSTF. There are two overall objectives for the GRCT project. The first objective is to provide experience in operating, testing, and analyzing structures in simultaneous cryogenic and high-temperature environments without mechanical loading. ${ }^{(6)}$ The second objective is use the GRCT to perform the LHSTF Integrated Systems Test prior to testing of large and expensive TAV cryogenic fuel tanks. Initial tests of the GRCT containing liquid nitrogen will be conducted in the existing high bay of the NASA Dryden Thermostructures Research Facility (TRF), Edwards, California. Subsequent liquid hydrogen tests will be conducted in the LHSTF.

A two-dimensional (2-D) model using the systems improved numerical differencing analyzer (SINDA' 85 ) was developed to predict the thermal behavior of the tank wall and cryogenic fluid prior to testing. ${ }^{(6,7)}$ To adequately characterize temperature gradients along the wall and within the fluid, temperature predictions from the 2-D model will be used to position sensors inside the tank. Predicted boiloff rates will be used to size the vent and pressure-regulation systems. Test scenarios will be designed based on the range of thermal responses generated by the 2-D model. This paper describes the results of 20 computational test cases evaluated with the 2-D GRCT model. The effects of fill level, heating profile, and cryogen type were characterized by boiloff rates, tank-wall and fluid temperatures, and tankwall heat fluxes. The effects of internal radiation and vapor mixing were also included in the analysis.

\section{Description of the Generic Research Cryogenic Tank}

Figures 1(a) and (b) show a cut-away view of the GRCT along the centerline and a section view through the $10-\mathrm{ft}$ center test section. The GRCT consists of a cylindrical stainless-steel pressure vessel ( $5 \mathrm{ft}$ diameter by $15 \mathrm{ft}$ length by $5 / 16 \mathrm{in}$. thick). The vessel is surrounded by $3 \mathrm{in}$. of

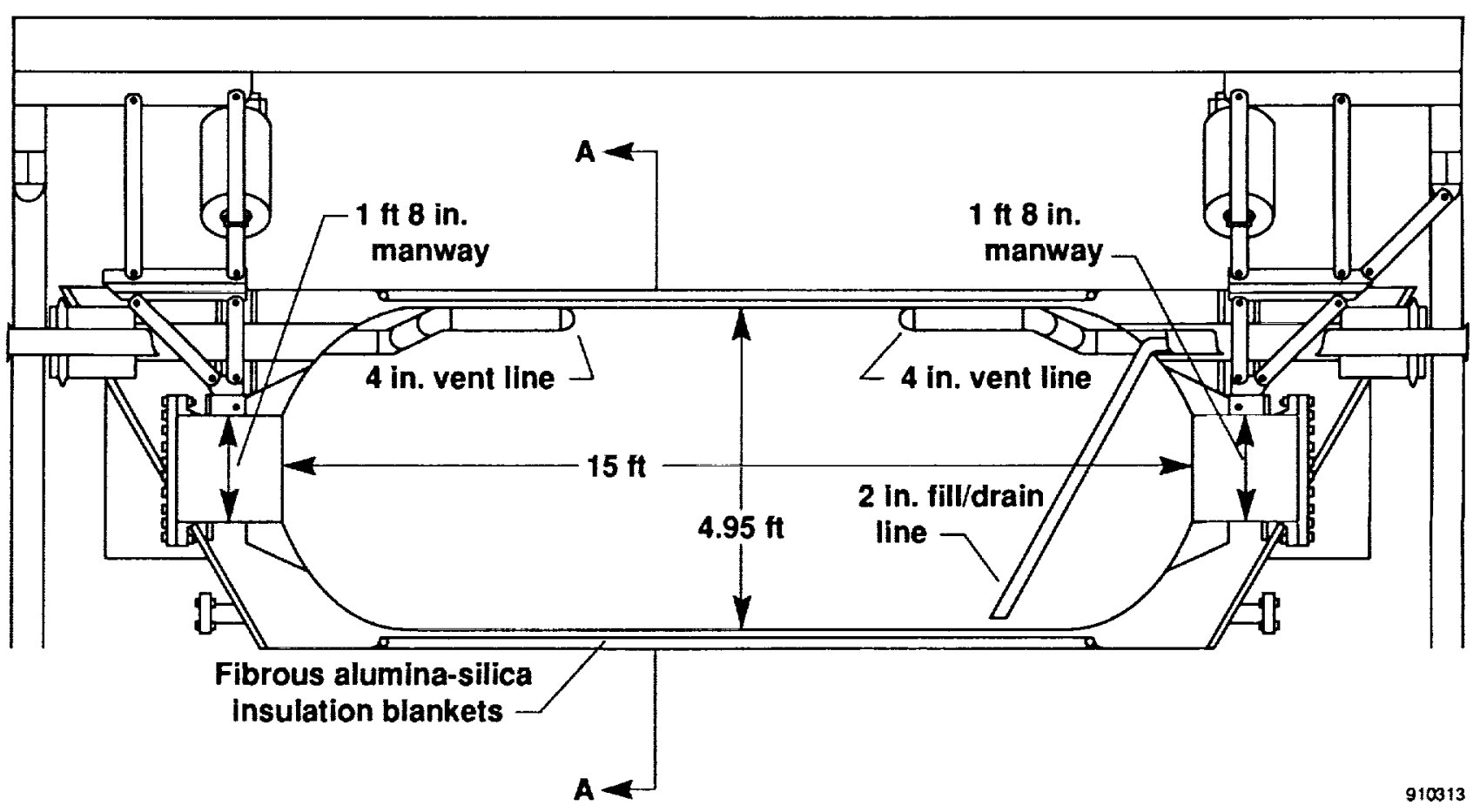

(a) Cut-away view (not to scale).

Fig. 1 Cut-away view of the GRCT and a section view of the test section. 


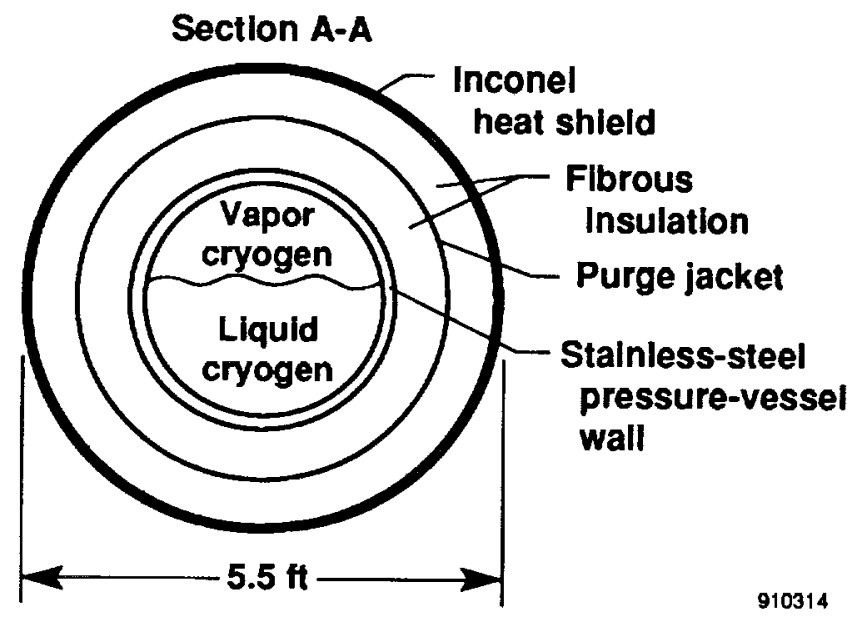

(b) Section A-A view.

Fig. 1 Concluded.

fibrous alumina-silica ceramic insulation $\left(8 \mathrm{lbm} / \mathrm{ft}^{3}\right.$ density) which is in turn surrounded by a thin Inconel ${ }^{\circledR}$ heat shield ( 0.030 in. thick). A purge liner of 0.005 -in. nickel foil is located within the insulation at $1.5 \mathrm{in}$. from the pressure vessel. Purge gas, helium for liquid-hydrogen tests and nitrogen (or helium) for liquid nitrogen tests, will be pumped into the end bell sections of the GRCT and channeled into the inner $1.5 \mathrm{in}$. of insulation next to the pressure vessel. During test operations, a clamshell quartz-lamp heater arrangement will be placed around the suspended GRCT. The quartz-lamp heaters radiate directly to the outer heat shield and provide a high temperature on the GRCT external surface. Additional design details are given in Stephens and Hanna. ${ }^{(6)}$

Figure 2 shows the simulated heating profiles applied to the outer heat shield of the GRCT. These profiles are composites derived from representative NASP thermal profiles and were used in several combinations. The "evenheating" test case used the high-temperature profile (peak temperature of $1960^{\circ} \mathrm{R}$ ) applied uniformly around the heat shield. To simulate TAV flight profiles, the two heating profiles shown in Fig. 2 were applied nonuniformly about the GRCT. For "hot-top" simulations, the high-temperature profile was applied to the GRCT upper heat shield quadrant while the low-temperature profile (peak temperature of $1260^{\circ} \mathrm{R}$ ) was applied to the lower quadrant. For "hotbottom" simulations, the profiles were reversed. During nonuniform heating, the heat shield side quadrants followed an average heating profile composed of the high-and low-temperature profiles. Although the profiles in Fig. 2 terminated at $3000 \mathrm{sec}$, computational runs continued to $10,000 \mathrm{sec}$ with the heat shicld temperature at $530^{\circ} \mathrm{R}$. Profiles similar to the computational profiles will be applied to the GRCT during testing in the TRF and LHSTF.

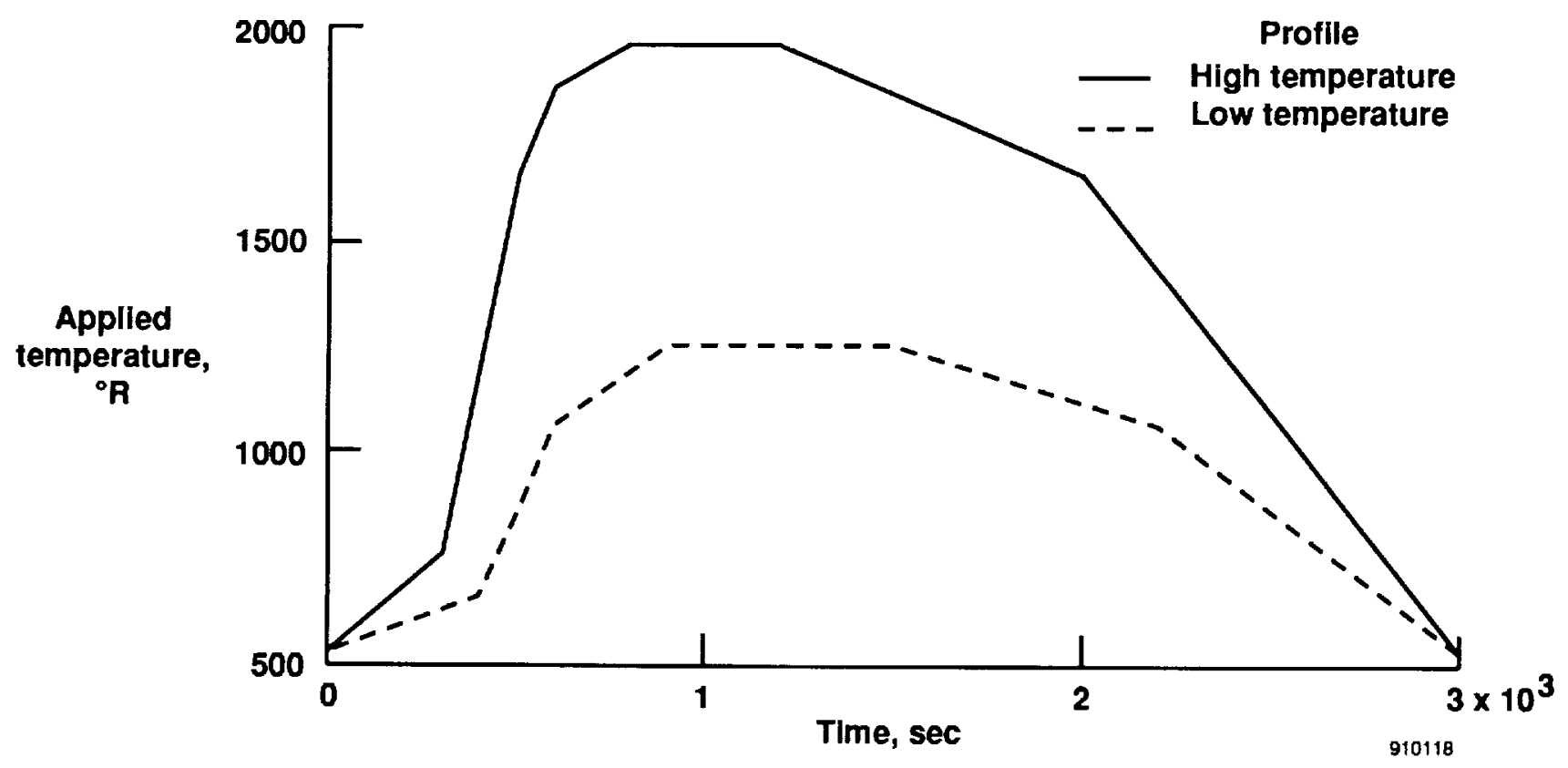

Fig. 2 Representative heating profiles to apply to the heat shields of the GRCT.

\footnotetext{
(Bnconel is a registered trademark of Huntington Alloy Products Division, International Nickel Company, Huntington, W.V.
} 


\section{Description of the Two-Dimensional Thermal Model}

The 2-D GRCT thermal model was created to characterize the thermal behavior of the ullage (the vapor region inside the tank), refine the calculation of cryogen boiloff, and examine the temperature gradients developed within the pressure-vessel wall. The 2-D model represented a 1-ftlong cylindrical cross section of the 10-ft-long GRCT test section and accounted for the cryogenic liquid and ullage. Figure 3 shows a schematic of the node layout used for the 2-D thermal model. The cryogenic fluid inside the pressure vessel was modeled by dividing the pressure-vessel cross-sectional area into 12 horizontal sections from top to bottom. The uppermost horizontal section was subdivided into three vapor nodes. Table 1 describes the distribution of liquid and vapor nodes and the wetted-wall area for each fill level considered in the computational test matrix. Both the pressure vessel and heat shield were divided into 26 nodes around the circumference of the tank. Each insulation section was in thermal contact with the pressure vessel on one side and the heat shield on the other. These insulation sections were subdivided into 12 nodes of increasing cross section ( $0.25 \mathrm{in}$. thickness/node) for a total of 312 insulation nodes. The model was capable of predicting vertical temperature gradients in the fluid, and circumferential and radial gradients in the tank wall and insulation. Additional details of the 2-D model construction are given by Stcphens and Hanna. ${ }^{(6)}$

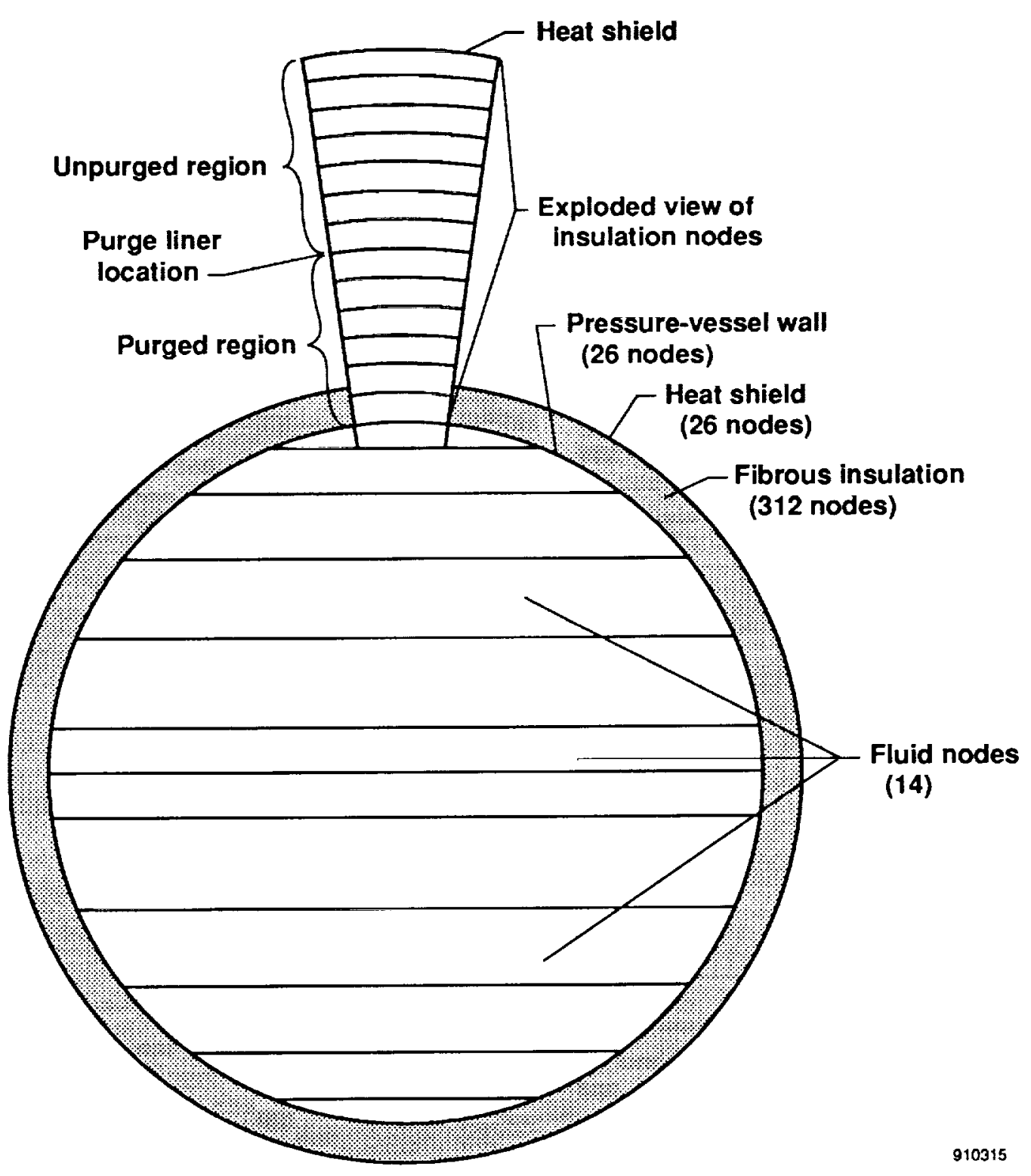

Fig. 3 Node layout for the GRCT 2-D thermal model. 
Table 1. The vapor and liquid node distribution and wetted wall area for the three fill levels of the computational test matrix.

\begin{tabular}{cccc}
\hline $\begin{array}{c}\text { Tank fill } \\
\text { level, } \\
\text { percent }\end{array}$ & $\begin{array}{c}\text { Number } \\
\text { of vapor } \\
\text { nodes }\end{array}$ & $\begin{array}{c}\text { Number } \\
\text { of liquid } \\
\text { nodes }\end{array}$ & $\begin{array}{c}\text { Wetted } \\
\text { wall } \\
\text { area* }^{*} \mathrm{ft}^{2}\end{array}$ \\
\hline 85 & 5 & 9 & 11.13 \\
50 & 8 & 6 & 7.85 \\
15 & 11 & 3 & 4.58 \\
\hline
\end{tabular}

Total internal area of the 2-D model was $15.71 \mathrm{ft}^{2}$

A matrix of computational test cases was defined to explore the effect of heating profile, cryogen (nitrogen as opposed to hydrogen), and fill level. The test matrix is summarized in Table 2 and includes the reference number for each test case. All test cases in Table 2 examined a stratified (conduction heat transfer only) vapor region. In addition to the 18 cases listed in Table 2, case NA50 was evaluated with vapor mixing and case NT15 was evaluated with internal radiation. Figure 4 shows the nomenclature used to describe the numerical test conditions provided in Table 2 . The SINDA' 85 model output for each computational test case included boiloff rates, tank-wall and fluid temperatures, heat fluxes, heat transfer coefficients, and temperature gradients around the tank wall.

\section{Results and Discussion}

\section{Boiloff Rate}

The time-dependence of boiloff is shown in Figs. 5 and 6. Figure 5 shows the effect of the heating profile on an 85-percent-full tank. In all cases, the highest boiloff rate was obtained with the even-heating profile, and the lowest boiloff occurred with the hot-top profile. The peak boiloff rate occurred at approximately 3,000 sec. Figure 6 shows the effect of fill level on nitrogen boiloff rates. For any

Table 2. Computational test matrix.

\begin{tabular}{lccccccc}
\hline \hline $\begin{array}{c}\text { Heating profile arrangement } \\
\text { (see Fig. 2) }\end{array}$ & $\begin{array}{c}\text { 85-percent liquid } \\
\text { fill level }\end{array}$ & $\begin{array}{c}50 \text {-percent liquid } \\
\text { fill level }\end{array}$ & $\begin{array}{c}\text { 15-percent liquid } \\
\text { fill level }\end{array}$ \\
\hline $\begin{array}{l}\text { Hot-top heating } \\
\text { High-temperature top quadrant } \\
\text { Low-temperature bottom quadrant }\end{array}$ & HT85 & NT85 & HT50 & NT50 & HT15 & NT15 \\
$\begin{array}{l}\text { Even heating } \\
\text { High-temperature all quadrants }\end{array}$ & HA85 & NA85 & HA50 & NA50 & HA15 & NA15 \\
$\begin{array}{l}\text { Hot-bottom heating } \\
\text { Low-temperature top quadrant } \\
\text { High-temperature bottom quadrant }\end{array}$ & HB85 & NB85 & HB50 & NB50 & HB15 & NB15 \\
\hline \hline
\end{tabular}

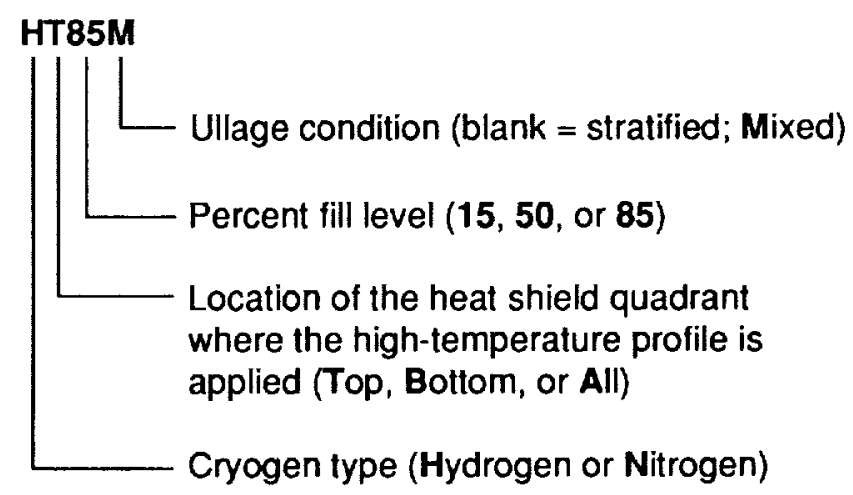

Fig. 4 Definition of the test case descriptors used to identify the conditions of each numerical test case shown in Table 2. 


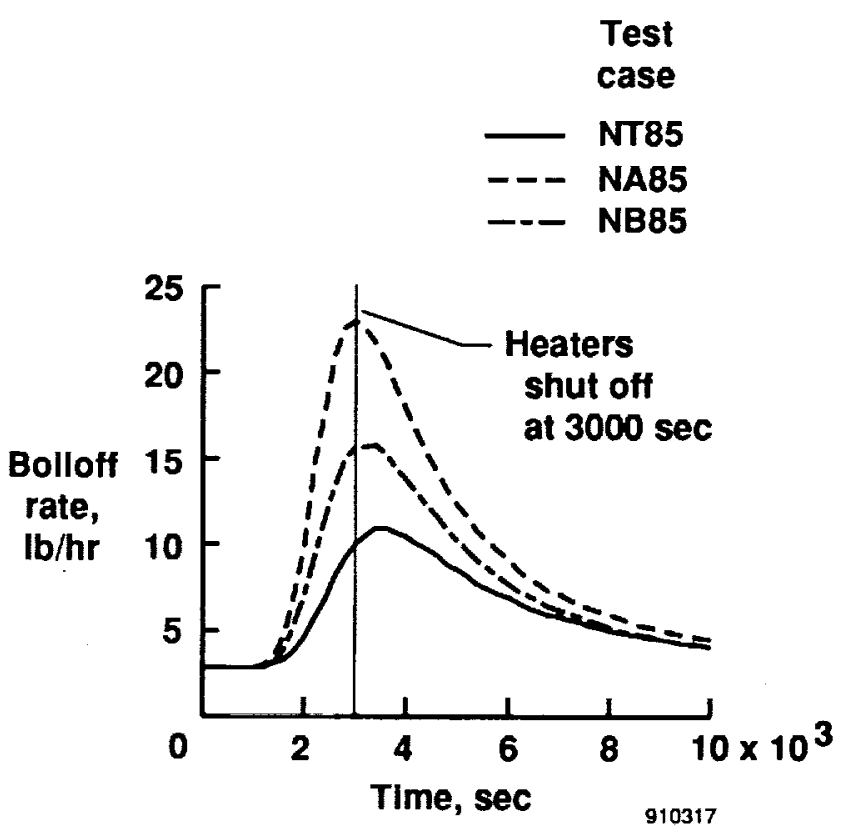

Fig. 5 Heating profile effect on the nitrogen boiloff rate as a function of time for an 85-percent fill level.
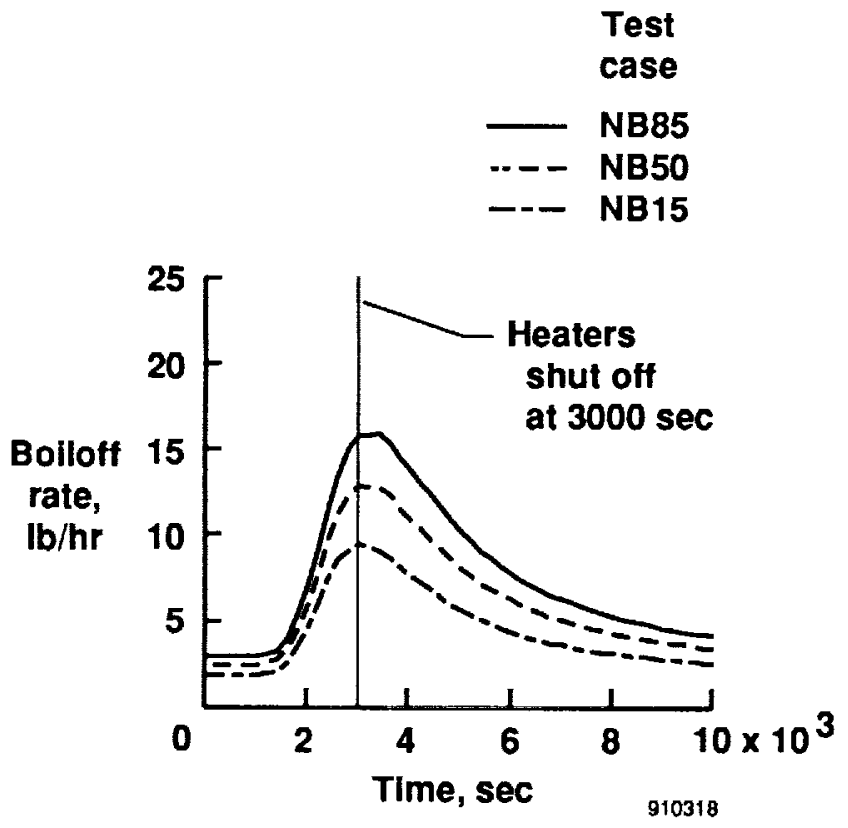

Fig. 6 Fill-level effect on the nitrogen boiloff rate as a function of time for the hot-bottom heating conditions.

given heating profile, boiloff was highest for a full tank and decreased linearly with fill level (fill level and wettedwall area were linearly related between 15 -percent and 85 percent full). Boiloff values in Figs. 5 and 6 were for the cylindrical model section only.
Boiloff rates for nitrogen and hydrogen are summarized in Table 3. The quantities of boiloff gas were similar for the two fluids. Since hydrogen has more than twice the heat of vaporization of nitrogen, an equivalent boiloff rate indicates that more than twice the quantity of heat entered the hydrogen tank compared with the nitrogen tank. An estimate of total tank boiloff can be calculated by multiplying the boiloff rate by 15 (ratio of the total tank wetted area to the 2-D model wetted area). The boiloff per square foot of wetted area can be calculated using values from Table 1 .

Table 3. Boiloff comparison for hydrogen and nitrogen.

\begin{tabular}{|c|c|c|c|c|}
\hline \multirow[b]{2}{*}{ Test cases } & \multicolumn{2}{|c|}{$\begin{array}{l}\text { Hydrogen boiloff, } \\
\text { Ib/hr }\end{array}$} & \multicolumn{2}{|c|}{$\begin{array}{l}\text { Nitrogen boiloff, } \\
\mathrm{lb} / \mathrm{hr}\end{array}$} \\
\hline & $\begin{array}{l}\text { Steady } \\
\text { state }\end{array}$ & Peak & $\begin{array}{c}\text { Steady } \\
\text { state }\end{array}$ & Peak \\
\hline HT85ॉ̃NT85 & & 9.39 & & 10.92 \\
\hline HA85/NA85 & 2.10 & 20.27 & 2.90 & 23.01 \\
\hline HB85/NB85 & & 14.05 & & 15.76 \\
\hline HT50/NT50 & & 6.15 & & 7.55 \\
\hline HA 50 NA 50 & 1.54 & 14.27 & 2.42 & 16.94 \\
\hline HB50/NB50 & & 10.94 & & 12.75 \\
\hline HT15/NT15 & & 2.99 & & 4.04 \\
\hline HA $15 /$ NA 15 & 1.01 & 8.44 & 1.82 & 10.30 \\
\hline HB15/NB15 & & 7.77 & & 9.41 \\
\hline
\end{tabular}

\section{Heat Fluxes to Liquid and Vapor}

The time histories of heat flux to tank nodes submerged in liquid were quantitatively similar to the boiloff curves (Figs. 5 and 6), since all incoming heat was converted to cryogen boiloff by the heat of vaporization. Heat that was transferred to the tank wall in contact with vapor warmed the vapor and did not contribute directly to boiloff rates.

Heat flux was calculated according to

$$
q^{\prime \prime}=h_{c}\left(\mathrm{~T}_{w}-\mathrm{T}_{f}\right)
$$

The temperature difference $\left(T_{w}-T_{f}\right)$ was generally less than $2{ }^{\circ} \mathrm{R}$ in the liquid phase and $10^{\circ} \mathrm{R}$ in the vapor phase.

The circumferential distribution of heat flux at the peak heat transfer rate for nitrogen is given in Fig. 7. The three curves presented correspond to the three fill levels subjected to the even-heating profile. Heat transferred to the tank wall above the liquid-vapor interface created a temperature gradient around the tank with the hottest point at the tank top. Heat was conducted around the ring of the tank (from top to bottom) until it reached the first wall node in contact with liquid. The liquid cryogen acted as a very large heat sink coupled to the tank wall by nucleate boiling, which allowed large quantities of heat to flow into the liquid. Consequently, 

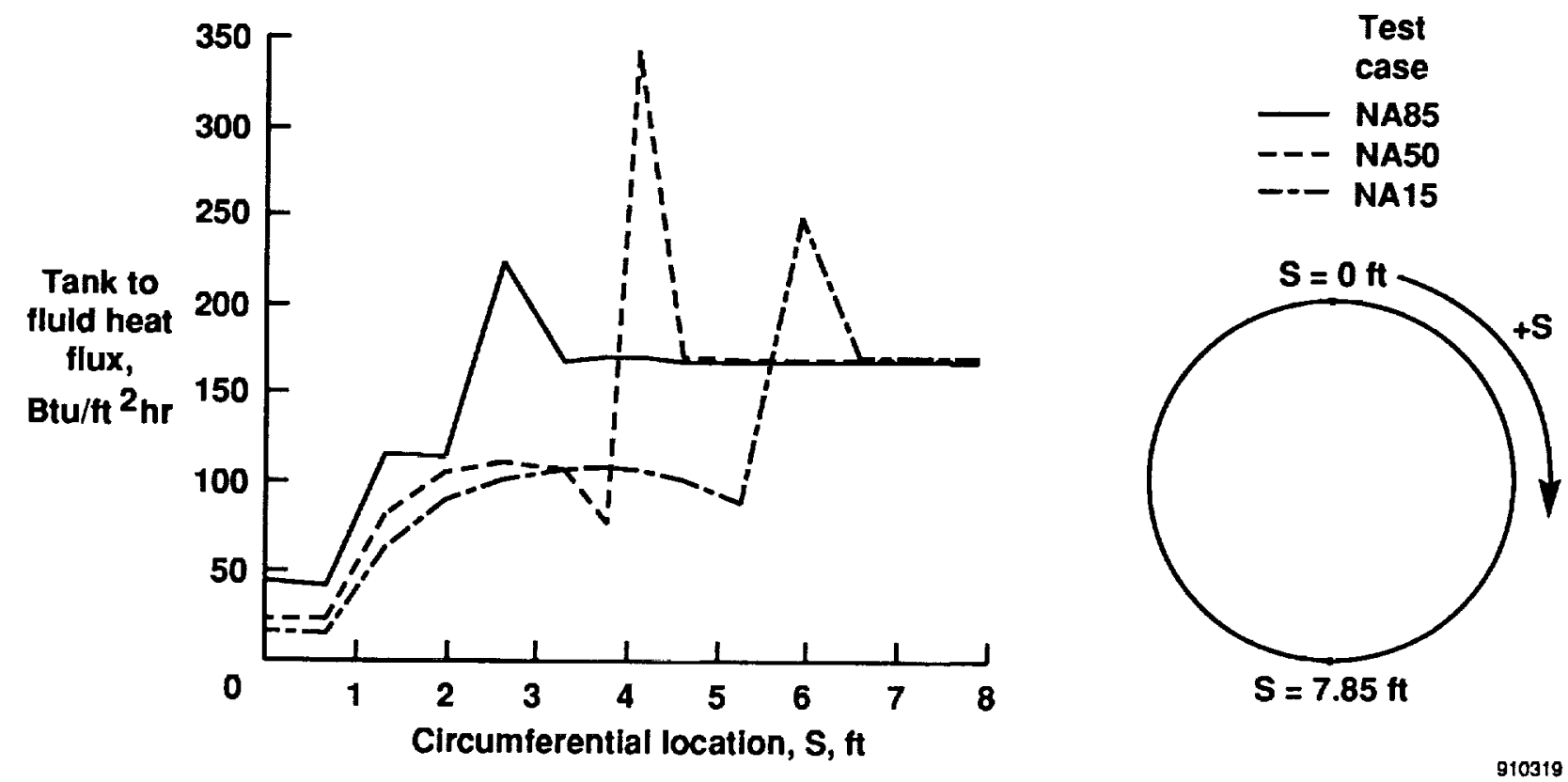

Fig. 7 Circumferential distribution of wall heat flux at the peak nitrogen heat transfer rate $(3000 \mathrm{sec})$ for the three fill levels subjected to the even-heating profile.

the wall node just below the liquid-vapor interface received a conductively-transferred heat load from the wall node directly above it, which produced the peak values shown in Fig. 7. The hot-top heating profiles exhibited behavior similar to those in Fig. 7, but peak liquid fluxes for hot-bottom heating usually occurred at the bottom of the tank.

Peak and average heat fluxes for all test cases are listed in Tables 4(a) and (b). The average wall-heat fluxes were calculated from the nodes in contact with liquid or vapor at the time the peak wall-heat flux occurred. Heat fluxes for nitrogen were considerably lower than for hydrogen, typically by a factor of 2 for nodes submerged in liquid and by a factor of 3 or 4 for nodes in contact with vapor. Peak hydrogenvapor fluxes exceeded peak liquid values for hot-top heating and were nearly equal to peak liquid values for even-heating cases. Peak nitrogen-vapor fluxes, however, were always substantially below liquid values.

Hydrogen fluxes in the liquid region were higher because the insulation system was partially purged with helium, which substantially increased its conductivity. Removing the effects of the helium purge gas reduced liquid heat fluxes for hydrogen to values comparable with nitrogen. The large hydrogen-vapor heat fluxes were caused by the high heat capacity of hydrogen vapor. Hydrogen vapor

Table 4. Peak heat-flux values for all computational test cases.

(a) Tank to vapor fluxes.

\begin{tabular}{cccccc}
\hline \hline & \multicolumn{3}{c}{ Peak tank to vapor fluxes, Btu/f $\mathrm{f}^{2} \mathrm{hr}$} \\
\cline { 2 - 3 } \cline { 5 - 6 } Test case & \multicolumn{2}{c}{ Hydrogen } & & \multicolumn{2}{c}{ Nitrogen } \\
\cline { 2 - 3 } \cline { 5 - 6 } & Maximum & Average & & Maximum & Average \\
\hline HT85/NT85 & 348.9 & 241.9 & & 94.8 & 60.2 \\
HA85/NA85 & 378.2 & 309.3 & & 117.6 & 79.7 \\
HB85/NB85 & 140.7 & 112.5 & & 47.1 & 31.1 \\
HT50/NT50 & 260.0 & 177.4 & & 79.6 & 49.5 \\
HA50/NA50 & 360.9 & 281.5 & & 124.4 & 81.2 \\
HB50/NB50 & 196.5 & 138.5 & & 66.0 & 38.9 \\
HT15/NT15 & 211.2 & 155.0 & & 65.9 & 48.0 \\
HA15/NA15 & 348.3 & 276.2 & & 120.1 & 86.9 \\
HB15/NB15 & 204.0 & 152.0 & & 67.1 & 45.1 \\
\hline \hline
\end{tabular}


(b) Tank to liquid fluxes.

Table 4. Concluded.

\begin{tabular}{cccccr}
\hline \hline & \multicolumn{3}{c}{ Peak tank to liquid fluxes, Btu/ft ${ }^{2} \mathrm{hr}$} \\
\cline { 2 - 3 } \cline { 5 - 6 } Test case & \multicolumn{2}{c}{ Hydrogen } & & \multicolumn{2}{c}{ Nitrogen } \\
\cline { 2 - 3 } \cline { 5 - 6 } & Maximum & Average & & Maximum & Average \\
\hline HT85/NT85 & 208.0 & 164.5 & & 146.4 & 82.7 \\
HA85/NA85 & 351.4 & 342.6 & & 223.8 & 173.5 \\
HB85/NB85 & 341.3 & 244.0 & & 129.9 & 119.7 \\
HT50/NT50 & 242.4 & 154.5 & & 233.0 & 91.0 \\
HA50/NA50 & 410.2 & 353.5 & & 347.7 & 193.6 \\
HB50/NB50 & 343.2 & 266.1 & & 231.7 & 140.7 \\
HT15/NT15 & 180.5 & 127.8 & & 140.8 & 73.9 \\
HA15/NA15 & 383.4 & 353.2 & & 249.0 & 189.4 \\
HB15/NB15 & 343.5 & 328.2 & & 195.2 & 173.9 \\
\hline \hline
\end{tabular}

heat fluxes remained twice as high as nitrogen values even without the helium purge gas effects.

Trends in wall-to-vapor heat flux as a function of fill level can be understood in terms of factors that drove the vapor temperature up or down relative to the wall temperature. The boiloff flow was the only source of cooling available to offset heat coming into the vapor space. Hot-bottom heating profiles produced much more boiloff than hot-top profiles. Consequently, more vapor was available for cooling in the hot-bottom cases than the hot-top cases. This accounted for decreasing flux with decreasing fill level for hot-top heating and increasing flux with decreasing fill level for hot-bottom heating. The even-heating cases transferred heat to the tank symmetrically, and therefore, the wall-to-vapor heat fluxes were nearly constant as a function of fill level.

Integrating the average heat flux around the tank provided an indication of how much heat was going into the tank when the maximum fluxes occurred. The heating rate distribution for the 2-D model section is summarized in Table 5 . In all nonuniform profiles, more heat was transferred to the cryogen tank with the hot-bottom profile than with the hot-top profile. This observation is consistent with the boiloff results but is not apparent from considering only the tank-wall temperatures that were higher for the hot-top profiles. Higher average tank temperatures would imply lower overall temperature driving forces and a correspondingly lower total heat input. Liquid in the tank acted as a thermal sink that absorbed heat without rising in temperature. The hot-bottom cases directed more heat into this thermal sink than the hot-top cases, and therefore, hot-bottom heating transferred more heat to the tank than hot-top heating.

\section{Tank-Wall and Fluid Temperatures}

Typical temperature distributions around the tank wall are shown in Fig. 8. The upper three curves define nitrogen tank-wall and vapor temperatures at steady state $(0 \mathrm{sec})$ and at the peak temperature $(6200 \mathrm{sec})$. At steady state, vapor and wall temperatures were so close that they could not be resolved on the scale of Fig. 8. As the heating profile progressed, the temperature difference between the tank wall and vapor reached $5^{\circ}$ to $10^{\circ} \mathrm{R}$ because of the high heat input. For the flat regions of the curves (beyond $S=$ $6 \mathrm{ft}$ ), the tank wall was submerged in liquid and remained slightly above the saturated liquid temperature throughout the heating period.

A top-to-bottom temperature differential of approximately $300^{\circ} \mathrm{R}$ was generated for hydrogen and nitrogen

Table 5. Heating rate distribution to the GRCT 2-D model section.

\begin{tabular}{|c|c|c|c|c|c|c|}
\hline \multirow[b]{2}{*}{ Test case } & \multicolumn{3}{|c|}{$\begin{array}{l}\text { Peak hydrogen heating } \\
\text { rates, Btu/hr }\end{array}$} & \multicolumn{3}{|c|}{$\begin{array}{l}\text { Peak nitrogen heating } \\
\text { rates, Btu/hr }\end{array}$} \\
\hline & Liquid & Vapor & Total & Liquid & Vapor & Total \\
\hline HT85/NT85 & 1830 & 1108 & 2938 & 920 & 276 & 1196 \\
\hline HB85/NB85 & 2715 & 516 & 3231 & 1332 & 142 & 1474 \\
\hline HT50/NT50 & 1213 & 1393 & 2607 & 715 & 389 & 1104 \\
\hline HB50/NB50 & 2091 & 1088 & 3179 & 1105 & 306 & 1411 \\
\hline HT15/NT15 & 586 & 1725 & 2311 & 339 & 534 & 873 \\
\hline HB15/NB15 & 1504 & 1692 & 3195 & 797 & 502 & 1299 \\
\hline
\end{tabular}




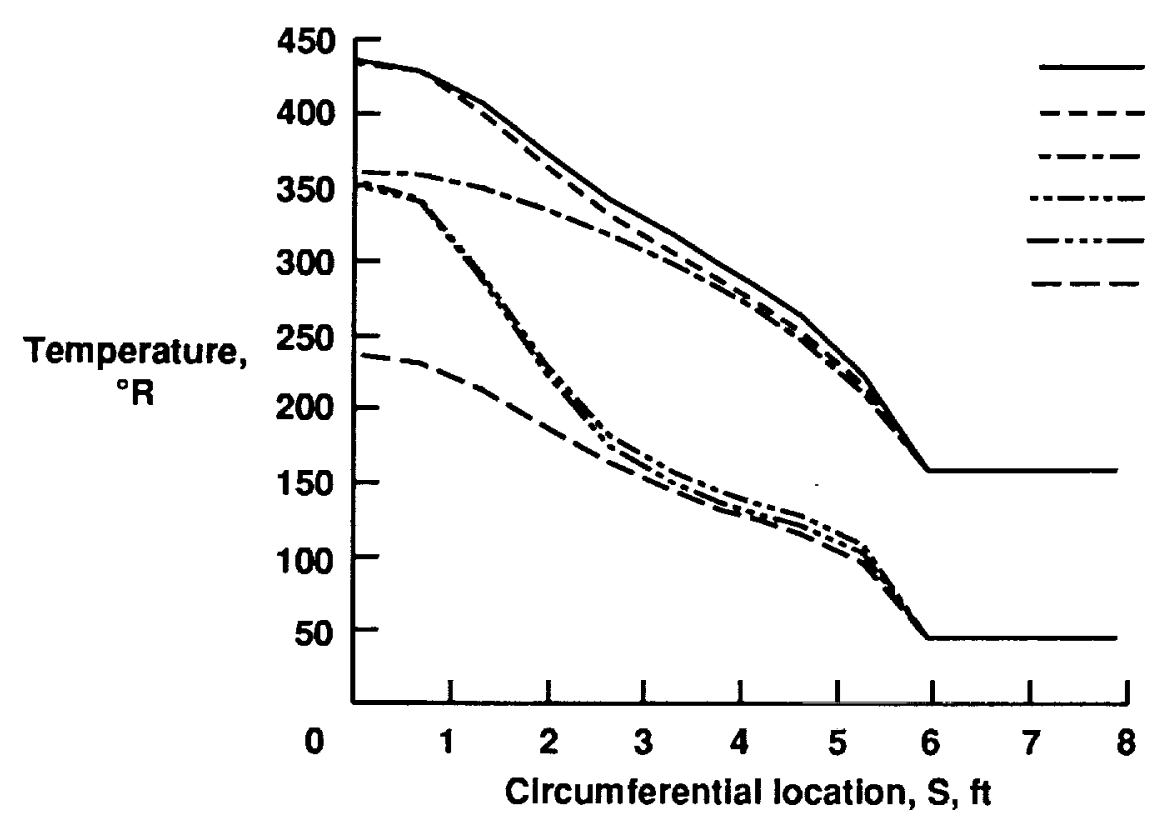

Test case

NT15 tank wall at $6200 \mathrm{sec}$

NT15 vapor at $6200 \mathrm{sec}$

NT15 tank wall and vapor at 0 sec

HT15 tank wall at $4800 \mathrm{sec}$

HT15 vapor at $4800 \mathrm{sec}$

HT15 tank wall and vapor at 0 sec

Fig. 8 Tank-wall and fluid temperatures as a function of circumferential location for nitrogen and hydrogen with the 15-percent fill level and hot-top heating profile test conditions.

when the tank temperature peaked. The large temperature differential that occurred during peak heating periods was caused by stratification in the vapor region. The $S$ shape of the hydrogen curve was caused by the magnitude and temperature dependence of the hydrogen vapor conductivity.

Tables 6(a) and (b) contain a list of tank-wall temperatures in the vapor region for nitrogen and hydrogen. Peak values always occurred at the top of the tank, and average values included all nodes in contact with vapor. The maximum transient values typically occurred at $6200 \mathrm{sec}$ for

Table 6. Steady-state and transient tank-wall temperatures in the vapor region as a function of cryogen type.

(a) Nitrogen.

\begin{tabular}{|c|c|c|c|c|}
\hline \multirow[b]{2}{*}{ Test case } & \multicolumn{2}{|c|}{$\begin{array}{c}\text { Steady-state } \\
\text { temperature, }{ }^{\circ} \mathrm{R}\end{array}$} & \multicolumn{2}{|c|}{$\begin{array}{c}\text { Maximum transient } \\
\text { temperature, }{ }^{\circ} \mathrm{R}\end{array}$} \\
\hline & Peak & Average & Peak & Average \\
\hline NT85 & & & 307.2 & 268.0 \\
\hline NA85 & 233.4 & 215.9 & 300.3 & 262.1 \\
\hline NB85 & & & 248.6 & 225.6 \\
\hline NT50 & & & 376.6 & 294.0 \\
\hline NA50 & 299.3 & 254.1 & 374.1 & 295.1 \\
\hline NB50 & & & 318.9 & 266.0 \\
\hline NT15 & & & 437.1 & 338.0 \\
\hline NA15 & 359.9 & 302.4 & 436.6 & 343.3 \\
\hline NB15 & & & 381.2 & 316.7 \\
\hline
\end{tabular}

(b) Hydrogen.

\begin{tabular}{|c|c|c|c|c|}
\hline \multirow[b]{2}{*}{ Test case } & \multicolumn{2}{|c|}{$\begin{array}{c}\text { Steady-state } \\
\text { temperature, }{ }^{\circ} \mathrm{R}\end{array}$} & \multicolumn{2}{|c|}{$\begin{array}{l}\text { Maximum transient } \\
\text { temperature, }{ }^{\circ} \mathrm{R}\end{array}$} \\
\hline & Peak & Average & Peak & Average \\
\hline HT85 & & & 198.3 & 141.7 \\
\hline HA85 & 113.3 & 89.9 & 163.3 & 119.2 \\
\hline HB85 & & & 113.3 & 89.9 \\
\hline HT50 & & & 290.0 & 169.3 \\
\hline HA50 & 180.2 & 123.6 & 269.2 & 157.0 \\
\hline HB50 & & & 193.8 & 124.3 \\
\hline HT15 & & & 354.0 & 207.6 \\
\hline HA 15 & 236.2 & 164.6 & 341.0 & 200.6 \\
\hline HB 15 & & & 256.9 & 167.5 \\
\hline
\end{tabular}

nitrogen and $4800 \mathrm{sec}$ for hydrogen, with the average values calculated at the time the maximum occurred.

The peak and average transient data from Tables $6(a)$ and (b) are plotted in three-dimensional form in Figs. 9(a) and (b). Looking across the graph shows the effect of fill level, and looking into the page gives the effect of heating profile. Tank-wall temperatures increased with decreasing fill level and increased with concentrated heat loads on the top of the tank. By comparing Figs. 9(a) and (b), it is clear that hydrogen and nitrogen exhibited similar behavior even though the magnitudes of the temperature changes were different. 


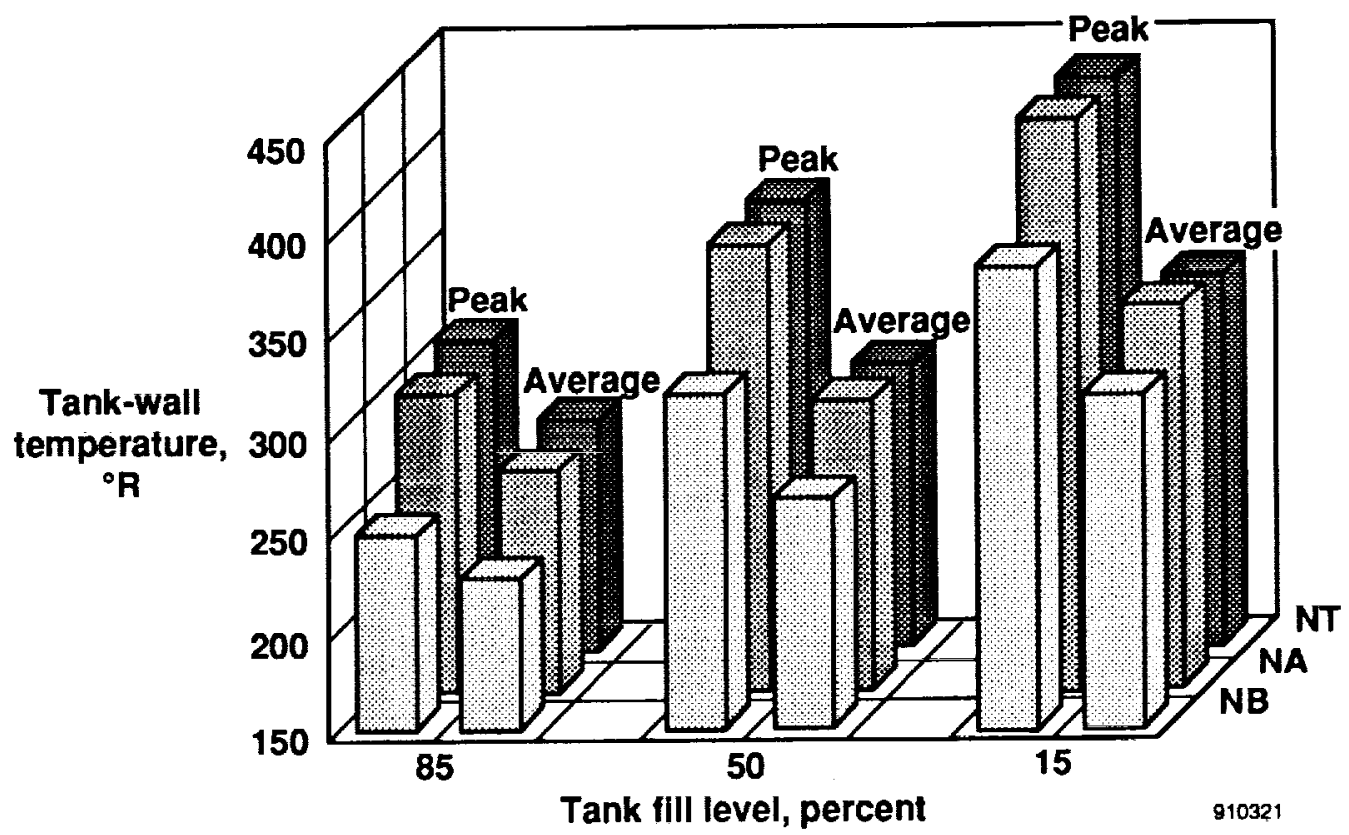

(a) Nitrogen.

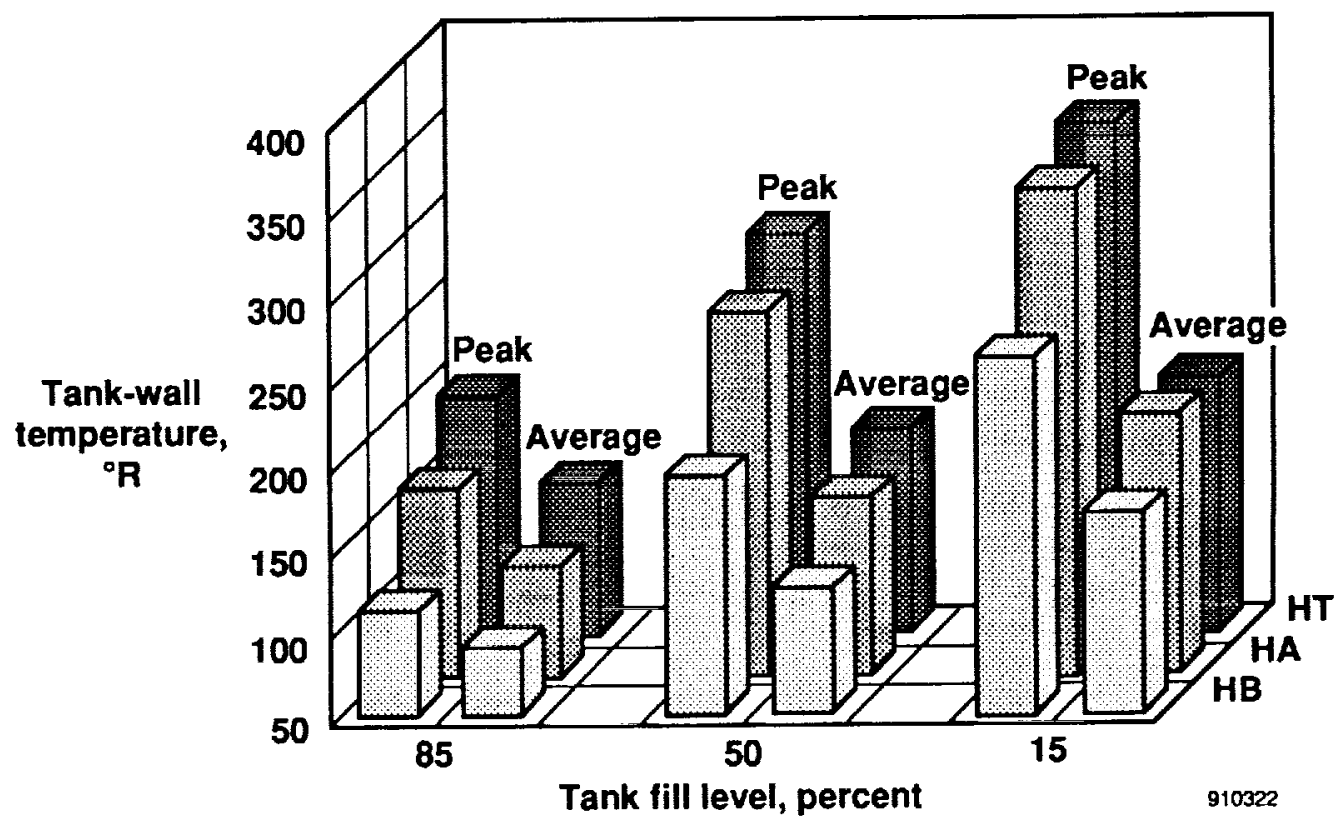

(b) Hydrogen.

Fig. 9 Peak transient and average tank-wall temperatures as a function of cryogen type, fill level, and heating profile arrangement.

The wall temperatures for the upper tank location $(\mathrm{S}=0 \mathrm{ft})$ with nitrogen are plotted as a function of time in Fig. 10. The curves show the temperatures at the tank top for all three fill levels and the two nonuniform heating profiles. The even-heating profile data fell between the two curves and were not plotted. Note that the $S=0 \mathrm{ft}$ temperatures for the hot-bottom cases (NB85, NB50, and NB15) did not change substantially from their steady-state values. However, the $S=0 \mathrm{ft}$ temperatures for the hot-top cases (NT85, NT50, and NT15) rose approximately $75^{\circ} \mathrm{R}$ during heating. Temperatures at other locations on the tank wall exhibited similar behavior to those shown in Fig. 10. 


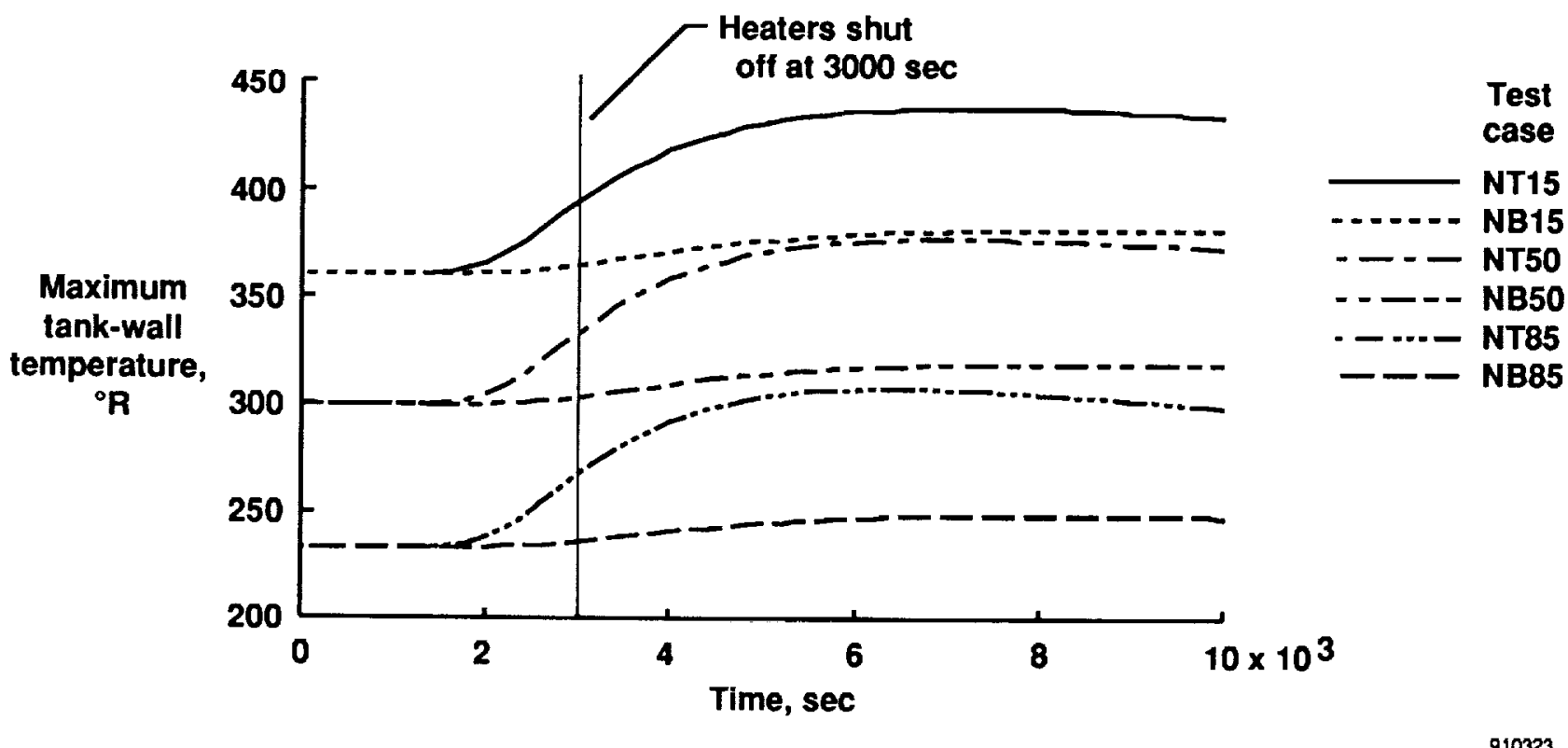

Fig. 10 Maximum tank-wall temperatures $(S=0 \mathrm{ft}$ ) as a function of time for nitrogen at three fill levels with the hot-top and hot-bottom heating profile arrangements.

In Figure 11 temperature distributions around the tank wall (at the time of maximum temperature) are plotted as a function of circumferential distance from the tank top. As in Fig. 10, data for the even-heating profile fell in-between the plotted curves. Boiling heat transfer in the liquid phase kept all tank and fluid temperatures close together for node locations covered by liquid. In the vapor phase, stratification resulting from conduction-dominated heat transfer caused increased temperatures and amplified the spread between different heating-profile cases.
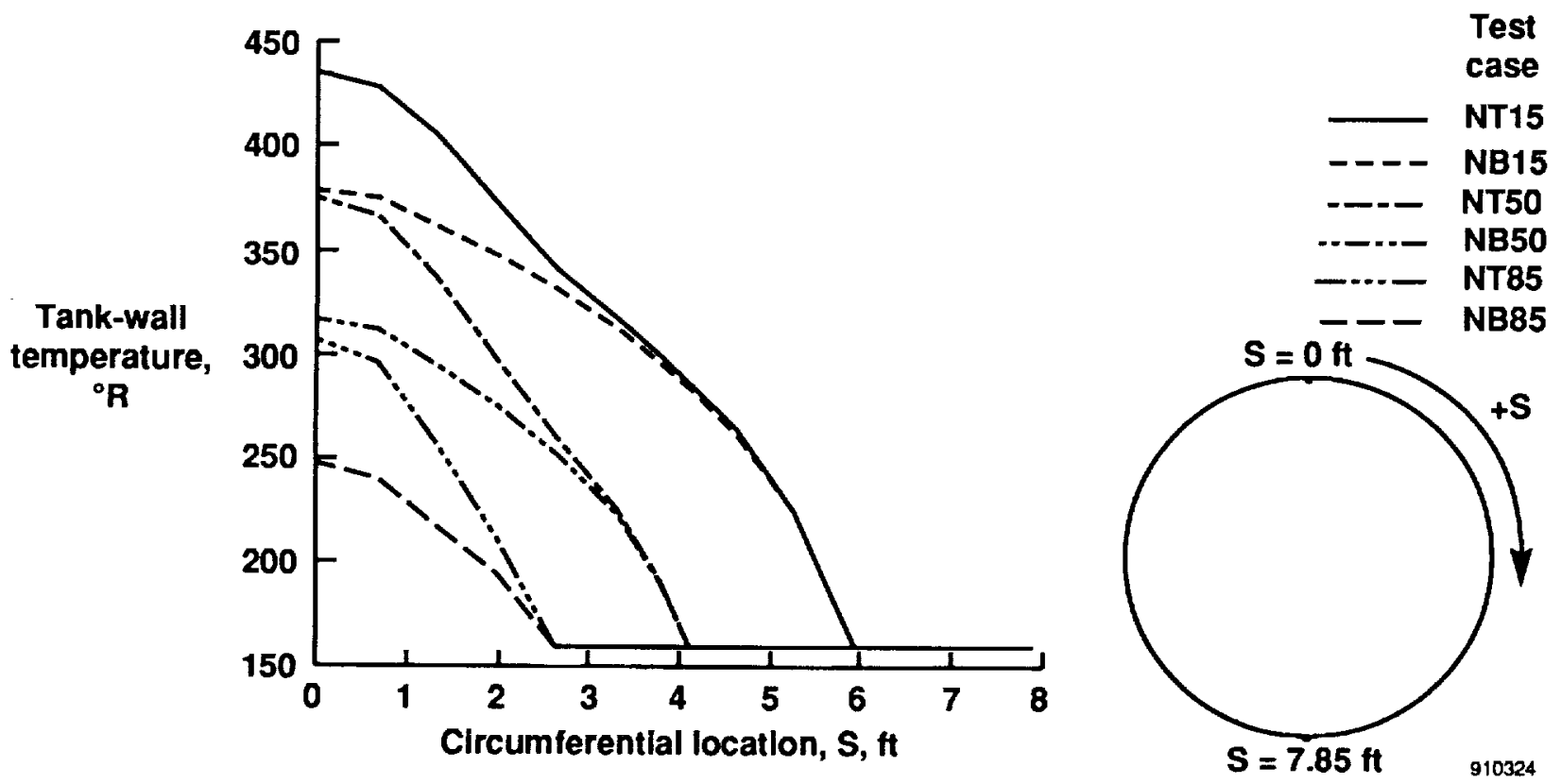

Fig. 11 Circumferential tank-wall temperature distributions at $6200 \mathrm{sec}$ for three nitrogen fill levels and the hot-top and hot-bottom heating profile arrangements. 


\section{Impact of Vapor Mixing}

All cases described in Table 2 assumed conductiondominated vapor-to-vapor heat transfer within the tank, which simulated a highly stratified tank and produced high temperatures at the tank top. During actual testing, heat transfer in the vapor space probably will be dominated by free convection, which will cause mixing in the vapor region. Along the sloped portions of the tank wall, buoyancy forces generated by warm vapor will induce circulation in the surrounding vapor. At the tank top where the hot surface is nearly horizontal, stratified vapor layers will be stable unless swept away by turbulent eddies generated along the curved tank wall. When considering the entire GRCT, the circulating flow patterns will have a helical component since boiloff flow originates at the liquid interface and moves toward the vents at either end of the tank.

No attempts were made to impose complex flow patterns into the vapor-to-vapor heat transfer because of SINDA'85 limitations. Instead, a "mixed" case was created by increasing the vapor-to-vapor thermal conductivity by a factor of 1000. These "mixed" conductors corresponded to a heat transfer coefficient between 0.01 and $0.10 \mathrm{Btu} / \mathrm{ft}^{2} \mathrm{hr}{ }^{\circ} \mathrm{R}$.

Case NA50 was evaluated with and without the "mixed" conductors to investigate the impact of vapor mixing. Temperatures around the tank wall are plotted in Fig. 12 for both cases. Although vapor mixing did not eliminate strati- fication, the steady-state maximum temperature dropped by $125^{\circ} \mathrm{R}$ and the peak temperature dropped by $150^{\circ} \mathrm{R}$. Unlike the wall-to-vapor heat transfer coefficient (which had very little effect on wall or vapor temperatures), vapor mixing substantially affected the overall thermal behavior of the ullage and tank wall.

\section{Internal Radiation Effects}

High temperatures in the upper regions of the tank, particularly when the tank is nearly empty, suggest that internal radiation could contribute significantly to heat transfer. A block of 255 radiation conductors, which linked all the internal tank nodes, was inserted into the NT15 case to more thoroughly investigate radiation effects. For the stainlesssteel tank a constant emissivity of 0.5 was used, which was considered conservative when compared to values of 0.3 and 0.4 for typical unpolished stainless. View factors were generated based on actual cylindrical geometry to account for three-dimensional radiation heat transfer.

The effect of radiation on tank temperatures is shown in Figs. 13 and 14. Figure 13 is a plot of temperature as a function of time for two locations on the tank wall. Adding internal radiation lowered the $S=0 \mathrm{ft}$ node temperature by $20^{\circ} \mathrm{R}$ and lowered an $S=3.29 \mathrm{ft}$ node temperature by $10^{\circ} \mathrm{R}$. The peak temperature distribution around the tank wall is plotted in Fig. 14. Wall temperatures above $300^{\circ} \mathrm{R}$ began to deviate from the pure conduction case, with the largest

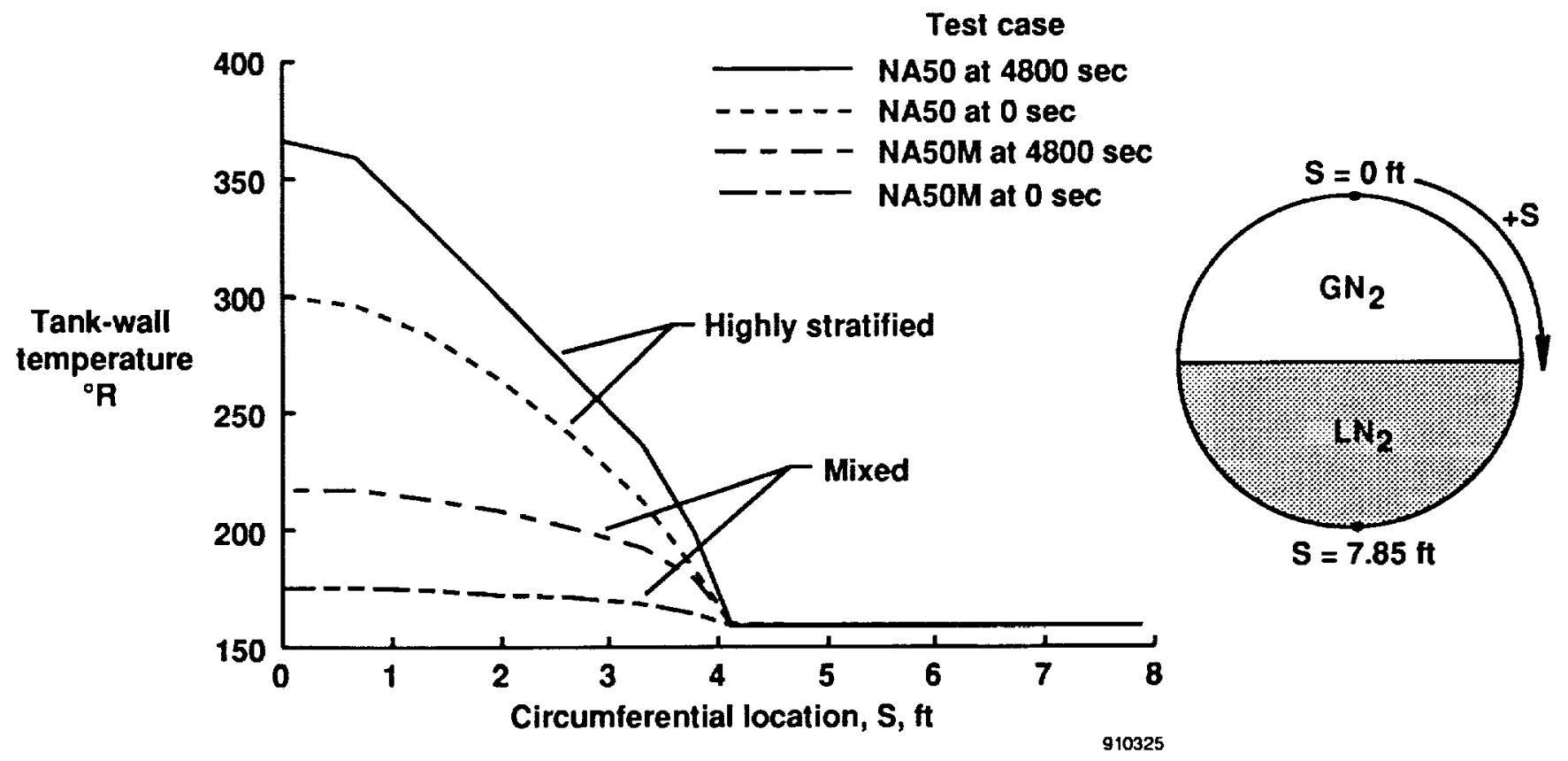

Fig. 12 Vapor mixing effects on the nitrogen tank-wall temperature distribution for the 50-percent fill level and even-heating test conditions. 
Test case

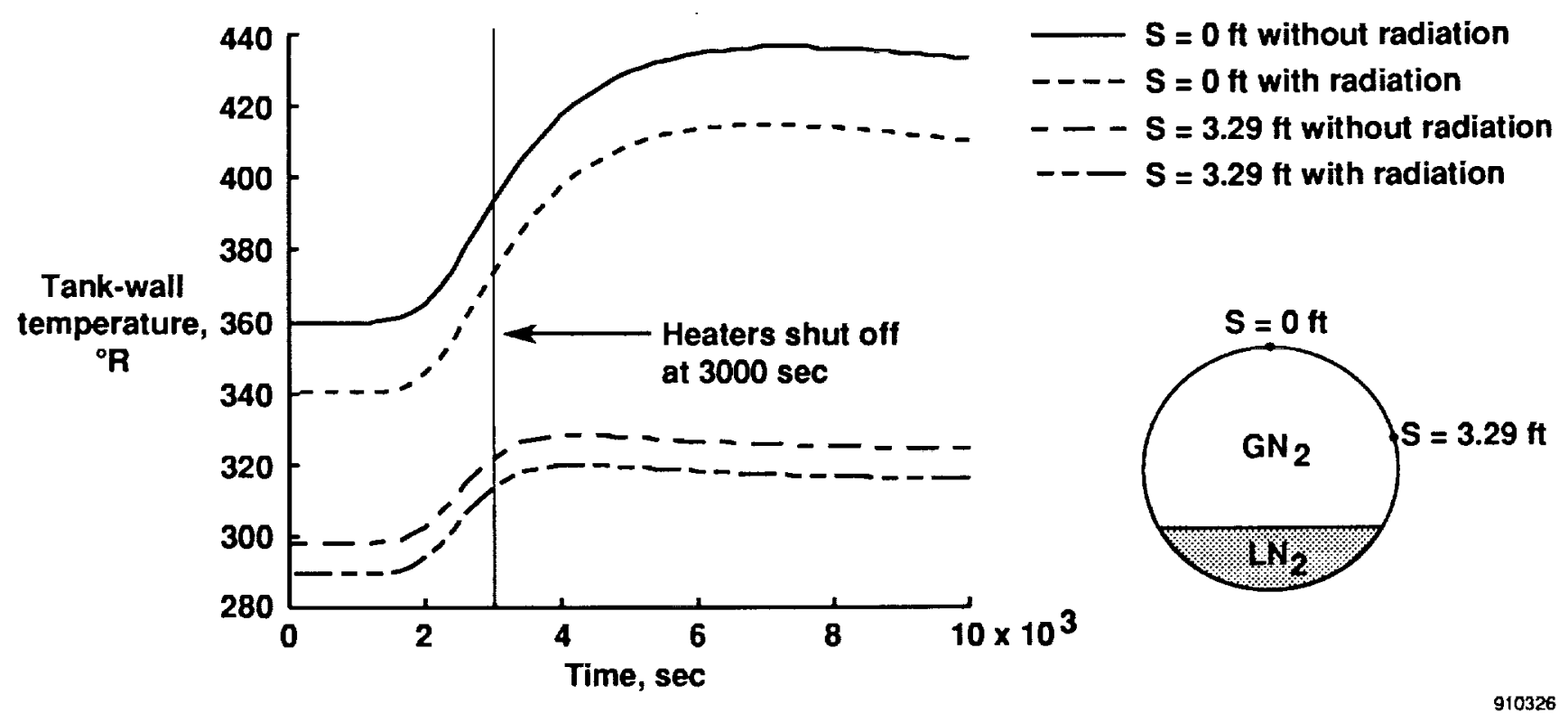

Fig. 13 Internal radiation effects on nitrogen tank-wall temperatures as a function of time for $\mathrm{S}=0 \mathrm{ft}$ and $\mathrm{S}=3.29 \mathrm{ft}$ with the NT15 test conditions.

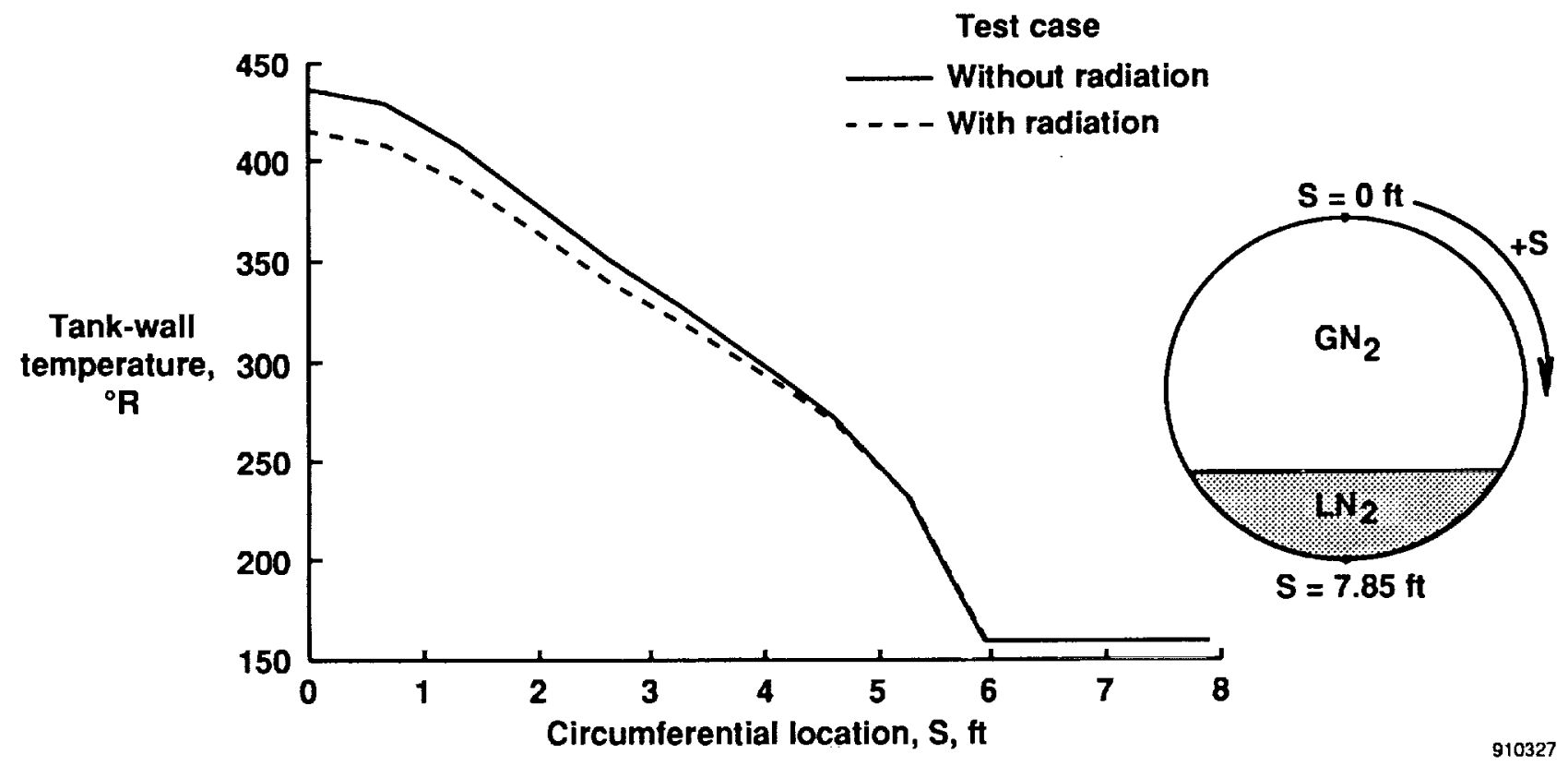

Fig. 14 Internal radiation effects on the peak nitrogen tank-wall temperatures as a function of circumferential location for the NT15 test conditions.

radiation effects located at the top of the tank. Adding radiation to the model lowered the top-to-bottom temperature difference by approximately 7 percent.

Table 7 lists boiloff rates for case NT15 with and without radiation at several times during the heating profile. The fractional change in boiloff varied from 1 percent to
6 percent. Based on these results, it is clear that internal radiation can impact temperatures and boiloff rates for highly stratified cases, but the effects are relatively small. Radiation effects at high fill levels or with "mixed" cases are substantially smaller than those in Table 7 because of lower tank-wall temperatures. 
Table 7. Internal radiation effect on boiloff rates for case NT15.

\begin{tabular}{cccc}
\hline \hline & \multicolumn{2}{c}{ Boiloff rate, } & \\
lb/hr & Percent \\
Time, sec & Radiation & No radiation & change \\
\hline 0 & 1.90 & 1.82 & 4.3 \\
3000 & 10.43 & 10.30 & 1.3 \\
6000 & 4.77 & 4.59 & 3.9 \\
9000 & 3.07 & 2.91 & 5.7 \\
\hline \hline
\end{tabular}

\section{Impact of Cryogen Type}

Nitrogen is often proposed as a "referee" fluid for hydrogen because it is easier to handle, less expensive, and requires only a fraction of hydrogen's safety precautions. In some cases, fluid and material properties will allow substitution of nitrogen for hydrogen, and in other cases, testing with liquid hydrogen is essential. In these computational test scenarios, nitrogen offered good performance in several areas, including overall thermal response, boiloff mass-flow rate, tank-wall temperature increases, and internal radiation effects. Nitrogen did not simulate the tank-wall heat fluxes in the vapor region. Since heat flux controls free convection in the vapor region, the internal heat transfer mechanisms within the two systems are likely to operate differently. In addition, nitrogen cannot replicate the high-heat capacity of hydrogen vapor.

Liquid nitrogen is approximately twelve times more dense than liquid hydrogen. Conducting structural tests using liquid nitrogen within a flight-weight fuel tank designed for liquid hydrogen could overstress the tank and produce test data of marginal value. In addition, the density differences affect the structural response of the system. Therefore, use of nitrogen as a substitute for hydrogen does not appear to be justified for TAV testing and verification.

\section{Applications to Flight Systems}

In comparing GRCT computational simulations with possible flight applications, the following conclusions can be drawn regarding thermal response of flight systems. As heat is added to a TAV tank, wall temperatures near the tank top will rise, and some vapor stratification is expected. The addition of warm pressurant gas to expel liquid hydrogen to the engines and cooling system will increase stratification and local wall temperatures. Heat flux to the liquid will increase at the liquid-vapor interface because of wall conduction from the ullage and from direct liquid-vapor interaction. Boiloff will decrease with decreasing fill level (wetted wall area) as the tank drains. The GRCT thermal response is therefore qualitatively similar to anticipated TAV behavior under flight conditions.
Although the GRCT models the behavior trends of TAV systems, specific values of heat flux or boiloff rate are probably not directly comparable. This is because the purged insulation system used in the GRCT has a poorer high-temperature thermal performance than possible high-temperature multilayer systems under development for TAVs. The peak temperatures that developed at the top of the GRCT, however, may be comparable to flight systems if stratification occurs in the vapor phase. The two primary mechanisms of cooling the tank top are by heat transfer to the vapor or conduction through the tank wall to cooler regions submerged in liquid cryogen. The conductive coupling for a thin-walled aluminum tank of a possible TAV is similar to the thick-walled stainless-steel conductivity of the GRCT. For example, the GRCT wall conductivity $(k \mathrm{~A} / \mathrm{L})$ corresponds to a 0.030 -in. wall made from 2219 aluminum. Since tank-wall conductivity is similar for the GRCT and aluminum flight tanks, the GRCT can provide insight into wall effects for TAV tanks. Further comparisons will require data from testing the GRCT and more specific performance analysis for TAV flight tanks.

\section{Concluding Remarks}

The Generic Research Cryogenic Tank (GRCT) twodimensional computational model predicted boiloff rates, fluid and wall temperatures, and heat fluxes for an extensive test matrix spanning three discrete fill levels and three heating profiles. Fill level and heating profile had a pronounced effect on all the model output parameters. Tank-wall and vapor temperatures increased and boiloff decreased as the tank fill level decreased. During heating, tank-wall temperatures rose as much as $250^{\circ} \mathrm{R}$ from their steady-state values because of stratification in the vapor phase. Vapor mixing greatly reduced stratification and was the dominant factor in ullage and tank wall thermal behavior. Heat fluxes to vapor and liquid behaved differently for nitrogen and hydrogen because of the helium-purged insulation and the difference in vapor heat capacity. Nitrogen was not considered as an acceptable "referee" fluid for hydrogen because of its density and thermal response. The GRCT thermal response qualitatively followed anticipated transatmospheric vehicle (TAV) behavior, and future tests may provide additional insight for TAV applications.

Based on the two-dimensional model predictions, extensive temperature measurements within the vapor phase will be required to adequately characterize mixing and thermal behavior of the system. Simulating the behavior of the GRCT under widely varying test conditions provided an envelope of temperatures, vent rates, heat fluxes, and transient responses. The envelope will greatly enhance test scenario development for both liquid nitrogen and liquid hydrogen testing. 


\section{References}

${ }^{1}$ Heathman, J.H., "Hydrogen Tankage for Hypersonic Cruise Vehicles - Phase I," Technical Report AFFDL-TR65-230, Aug. 1966.

${ }^{2}$ Heathman, J.H., "Hydrogen Tankage Application to Manned Aerospace Systems Phases II \& III," Technical Report AFFDL-TR-65-75, Volumes I and III, Apr. 1968.

${ }^{3}$ Urie, David M., and Roug, George P., "Zero Length Launch Trans Atmospheric Vehicle (ZEL TAV) Structural Technology Validation Program - Final Report," USAF Contract F18600-86-C-4000, Lockheed Aeronautical Systems Co., July, 1988.

${ }^{4}$ Hardy, Terry L., and Tomsik, Thomas M., Prediction of the Ullage Gas Thermal Stratification in a NASP Vehicle
Propellant Tank Experimental Simulation Using FLOW-3D, NASA TM-103217, 1990.

${ }^{5}$ Teare, D., and Kubik, D., "Integrated Cryo-Tank Thermodynamic Analysis Method," AIAA-90-5214, AIAA Second International Aerospace Planes Conference, Orlando, Fl., Oct. 1990.

${ }^{6}$ Stephens, Craig A., and Hanna, Gregory J., "Thermal Modeling and Analysis of a Cryogenic Tank Design Exposed to Extreme Heating Profiles," AIAA-911383, AIAA 26th Thermophysics Conference, Honolulu, Hawaii, June, 1991. Also published as NASA CR-186012.

${ }^{7}$ Cullimore, B.A., Goble, R.G., Jensen, C.L., and Ring, S.G., "SINDA'85/FLUINT Systems Improved Numerical Differencing Analyzer and Fluid Integrator Version 2.2," Cosmic Program \#MSC-21528, NAS9-17448, Aug. 1986. 


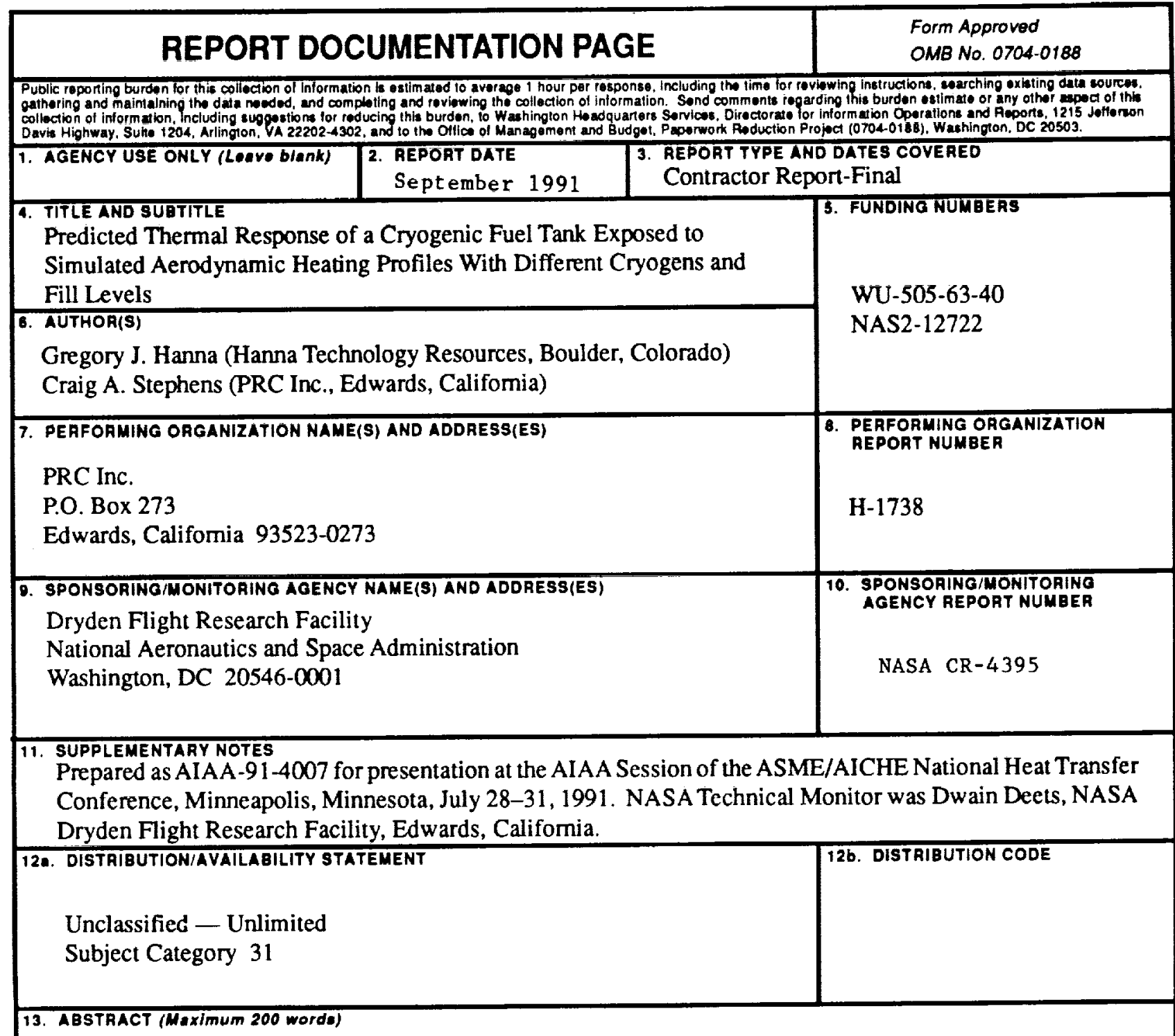

A two-dimensional finite-difference thermal model was developed for the Generic Research Cryogenic Tank (GRCT). The model was used to predict the effects of heating profile, fill level, and cryogen type prior to experimental testing. These numerical predictions will assist in defining test scenarios, sensor locations, and venting requirements for the GRCT experimental tests. Boiloff rates, tank-wall and fluid temperatures, and wall heat fluxes were determined for 20 computational test cases. The test cases spanned three discrete fill levels and three heating profiles for hydrogen and nitrogen. Large temperature gradients developed in the vapor region of the tank when the vapor was allowed to stratify, but vapor mixing greatly reduced the top-to-bottom temperature gradient. The thermal response of the GRCT was qualitatively similar to anticipated transatmospheric vehicle (TAV) behavior. Nitrogen simulations deviated from hydrogen simulations in several key areas, particularly where the vapor heat capacity contributed to the system themal response. The intemal radiation and wall-to-vapor heat transfer effects were small companed with the effect of vapor mixing.

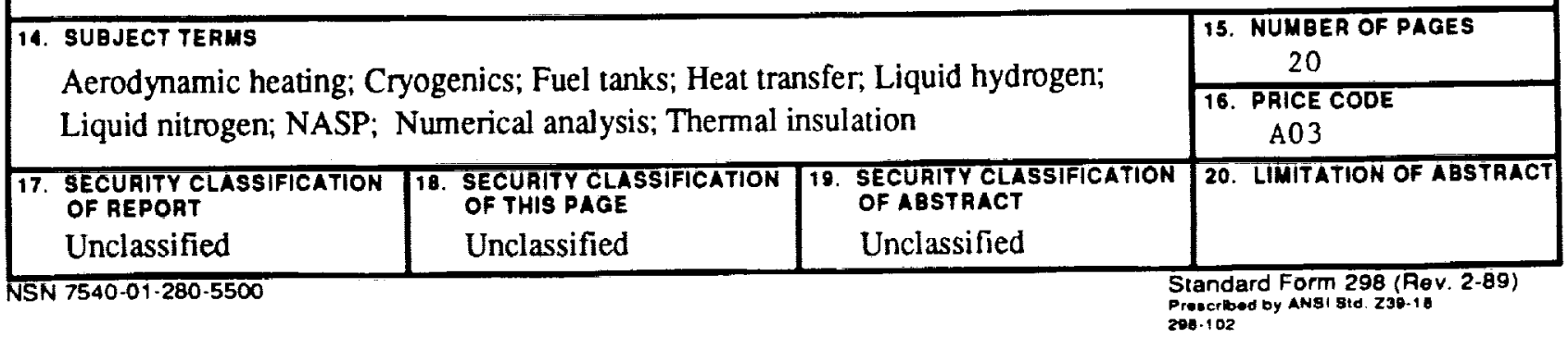

